\title{
Keeping Pace with Pharmaceutical Innovation: The Importance of the NICE Methods Review
}

\author{
Paul Catchpole $^{1} \cdot$ Victoria Barrett $^{1}$
}

Published online: 24 April 2020

(c) The Author(s) 2020

\section{Introduction}

The National Institute for Health and Care Excellence (NICE) plays a vitally important role in ensuring patients get timely access to new medicines that are clinically and cost effective. The methods used by NICE to appraise medicines (and other health technologies) [1] are currently undergoing extensive review. As noted by Boysen and Watson [2], this was an important commitment agreed to in the 2019 Voluntary Scheme for Branded Medicines Pricing and Access [3].

The review is arguably the most important examination of NICE's methods in its 20-year history, because the types of new medicines in the pharmaceutical industry pipeline are very different to those seen previously. Advances in science mean we have new medicines for previously untreatable diseases, often very specific to a small sub-set of patients. Medicines are being developed to treat patients earlier on in the disease pathway, with novel mechanisms of action that in some cases are potentially curative [4-7]. There are significant developments in areas like gene-editing technology, stem cell treatments, exosomes and chimeric antigen receptor T-cell therapies [8].

As these medicines come to the market, health technology assessment (HTA) methods need to evolve to ensure their value is comprehensively captured. NICE's methods review provides a timely opportunity to make the changes needed, so that patients can access the latest treatments.

This piece comments on the following papers https://doi. org/10.1007/s40273-020-00888-5, https://doi.org/10.1007/s4027 3-019-00882-6.

Victoria Barrett

vbarrett@abpi.org.uk

1 The Association of the British Pharmaceutical Industry, London, UK

\section{Key Areas for Focus}

Sculpher and Palmer consider key areas of NICE's methods and developments in approaches to economic evaluation [9]. NICE has set out the expectation that some of the challenges identified may not be resolved and will likely be beyond the reach of the current review [2]. We believe the broad scope set for the review, with appropriate support from key stakeholders, will allow NICE to make the changes that are necessary. Ensuring NICE uses state of the art HTA methods is important from a global perspective, not only to ensure NICE is seen as a world-leading HTA body but also to help make the UK an attractive place for life sciences companies to invest now that we have left the European Union.

From across the many important areas included in the review, we have selected three areas on which to focus in this response.

\subsection{Broader Value Framework}

The quality-adjusted life-year (QALY) framework is important because it provides a comparable measure of health benefit for different technologies in different therapy areas. However, it has been argued that a rigid QALY-based decision-making framework does not capture all of the benefits of a health intervention that are accrued by patients, their families and carers, the NHS and society [10].

NICE acknowledges this to some extent by attempting to capture a small number of other factors or "elements of value' (i.e., beyond QALY gains) in a deliberative way, but the impact of these in and across different Appraisal Committees is not always clear or consistent [9]. There are also currently two circumstances where NICE applies 'modifiers' via QALY weightings, for end-of-life (EOL) medicines [1] and for ultra-rare disease medicines in the highly specialised technologies programme [11].

When introduced in 2009, the EOL criteria reflected the need to provide access to new cancer medicines that were 
primarily being developed (at least initially) for end-stage cancers [12]. We argue this binary measure now needs to evolve to better account for improvements in quality of life as well as increased life expectancy, acknowledging improvements in the standard of care, with medicines being licensed for use earlier in the disease pathway and with novel mechanisms of action to target tumours and help combat drug resistance [13]. The EOL criteria could be replaced with a severity-based modifier that is not binary and reflects a broader view of the impact a condition has on a patient's life. This would enable NICE to take forward concepts first worked up in its value-based assessment consultation in 2013, which considered how 'burden of illness' could be incorporated into the decision-making framework.

In addition, the review needs to consider how NICE's decisions can more comprehensively reflect the value of medicines by more explicitly including other value elements and non-direct health effects; for example, rarity of the disease treated, experience of care and impact on families and carers, in a broader decision-making framework. A more formal mechanism for transparently taking these factors explicitly into account is needed.

\subsection{Managing Uncertainty}

Uncertainty is an unavoidable aspect of healthcare decision making, and this is particularly true in HTA [14]. There is an increasing gap emerging between the evidence requirements needed for regulatory decisions and those for reimbursement, and a growing tension between the desire to provide patients with fast access to new medicines and making reliable decisions to support routine commissioning. The characteristics of the types of new medicines in the pipeline, the emergence of more targeted therapies for ever smaller patient populations and the earlier scheduling of appraisals, all amplify this challenge [7, 8].

Mechanisms like the Cancer Drugs Fund, and potentially the proposed Innovative Medicines Fund [15], have helped provide pragmatic solutions by enabling NICE to grant conditional approvals whilst additional data is collected, benefiting thousands of NHS patients. However, these mechanisms are only suitable for situations where additional data collected over 2-3 years can help address the uncertainty. There needs to be a better distinction between uncertainty that can be addressed at the time of appraisal or through short-term additional data collection and that which is inherent in the condition/medicine that will not be resolved in the short term, or potentially cannot be resolved due to ethical considerations. The review should seek to improve how NICE Appraisal Committees are presented with and subsequently consider different types of uncertainty in a more pragmatic manner. Introducing more methodological complexity is not necessarily the answer in an already resource constrained environment. A strategic dialogue between the government, NHS England, NICE and the industry needs to establish a shared view of the appetite for decision risk and how it should be shared and managed. This has implications for both NICE's appraisal methods and how managed access agreements are negotiated with NHS England.

\subsection{Discounting}

The discount rate currently used by NICE [1] is no longer aligned to HM Treasury Green Book guidance [16] and the latest evidence [17-21]. There is some debate in the academic literature as to whether discount rates for costs and health effects should be common or differential [17-21]. Given the costs included in economic models are not accounted for in the NHS as equivalent to QALYs, there is a case for having a differential discount rate, akin to NICE's perspective on this between 1999 and 2003, when discount rates of $6 \%$ for costs and $1.5 \%$ for health effects were applied [20]. The review should seek to align the discount rate for health effects to HM Treasury Green Book at 1.5\% [16].

\section{Making Meaningful, Evidence-Based Changes in a Sustainable Way}

NICE's role is pivotal for the pharmaceutical industry and the medicines ecosystem but, as Boysen and Watson [2] point out, there are other inextricably linked parts of the system and there is an overlaying normative view on what NICE can consider as 'cost effective'. We believe the review can deliver meaningful change but agree more work needs to be done across the system to ensure that (a) the NHS can continue to use the most effective treatments and (b) the UK remains a priority launch market for global pharmaceutical companies.

The changes made to NICE's methods must be evidencebased, pragmatic and able to be operationalised efficiently within a time- and resource-constrained environment. We support NICE's ambition to find the right balance in its new Methods Manual, ensuring it is sufficiently prescriptive to support companies with their submissions whilst retaining flexibility so that appraisals are appropriate for each medicine in question and its supporting evidence package [2].

Meaningful changes can be made in a sustainable way given the existing affordability mechanisms in place to manage expenditure on branded medicines, including the Voluntary Scheme for Branded Medicines Pricing and Access and the Statutory Scheme [3]. Together these ensure complete predictability of spend for the branded medicines bill for the NHS, which will not grow by more than $2 \%$ in any of the next 4 years. This guaranteed level of maximum NHS spend provides the necessary financial headroom to allow NICE to introduce meaningful changes to its methods without risk to the NHS budget. 


\section{Conclusion}

The evolution of the regulatory and HTA environments in the UK will be critical success factors in attracting future investment from the global life sciences industry now that we have left the European Union. In turn, NICE's methods play a key role in helping to achieve this if they can be made fit for the future and able to comprehensively assess the value of the medicines in the pharmaceutical industry pipeline. A continuous approach to evolving appraisal methods based on the latest evidence and need for adaptation will help sustain NICE as a world-leading HTA body and the NHS as a world-leading healthcare system.

\section{Compliance with Ethical Standards}

Funding No specific funding was used for work detailed in this paper. The authors are employed by the Association of the British Pharmaceutical Industry. PC is a member of the NICE Methods Review Working Group. VB has deputised at some of the NICE Methods Review Working Group meetings.

Open Access This article is licensed under a Creative Commons Attribution-NonCommercial 4.0 International License, which permits any non-commercial use, sharing, adaptation, distribution and reproduction in any medium or format, as long as you give appropriate credit to the original author(s) and the source, provide a link to the Creative Commons licence, and indicate if changes were made. The images or other third party material in this article are included in the article's Creative Commons licence, unless indicated otherwise in a credit line to the material. If material is not included in the article's Creative Commons licence and your intended use is not permitted by statutory regulation or exceeds the permitted use, you will need to obtain permission directly from the copyright holder.To view a copy of this licence, visit http://creativecommons.org/licenses/by-nc/4.0/.

\section{References}

1. NICE. 2013. Guide to the methods of technology appraisal. NICE, London. https://www.nice.org.uk/guidance/pmg9/resources/guide -to-the-methods-of-technology-appraisal-2013-pdf-2007975843 781. Accessed 2 Apr 2020.

2. Boysen M, Watson I. Reflections on NICE's uptake of new methods: past, present, and the 2020 review. PharmacoEconomics. 2020;38:243-5. https://doi.org/10.1007/s40273-020-00888-5.

3. DHSC. 2019. The 2019 voluntary scheme for branded medicines pricing and access: chapters and glossary. DHSC, London. https ://assets.publishing.service.gov.uk/government/uploads/syste $\mathrm{m}$ /uploads/attachment_data/file/761834/voluntary-scheme-forbranded-medicines-pricing-and-access-chapters-and-glossary. pdf. Accessed 2 Apr 2020.

4. NICE. 2016. Exploring the assessment and appraisal of regenerative medicines and cell therapy products. NICE, London. https:// www.nice.org.uk/Media/Default/About/what-we-do/Science $\% 20$ policy\%20and\%20research/Regenerative-medicine-study-march -2016.pdf. Accessed 2 Apr 2020.

5. Marsden G, Towse A. Exploring the assessment and appraisal of regenerative medicines and cell therapy products: is the NICE approach fit for purpose? OHE consulting report. London: Office of Health Economics; 2017.

6. Jönsson B, Hampson G, Michaels J, Towse A, von der Schulenburg J-MG, Wong O. Advanced therapy medicinal products and health technology assessment principles and practices for value-based and sustainable healthcare. Eur J Health Econ. 2019;20:427-38. https://doi.org/10.1007/s10198-018-1007-x.

7. Pharmaprojects. 2019. Pharma R\&D annual review 2019. Informa, London. https://pharmaintelligence.informa.com/ / media/informa-shop-window/pharma/2019/files/whitepapers/ pharma-rd-review-2019-whitepaper.pdf. Accessed 2 Apr 2020.

8. EFPIA. 2019. Pipeline review of innovative therapies. EFPIA, Brussels. https://www.efpia.eu/media/412124/pipeline-review-ofinnovative-therapies-2018-summary-deck-final.pptx. Accessed 2 Apr 2020.

9. Sculpher M, Palmer S. After 20 years of using economic evaluation, should NICE be considered a methods innovator? PharmacoEconomics. 2020;38:247-57. https://doi.org/10.1007/s4027 3-019-00882-6.

10. Lakdawalla DN, Doshi JA, Garrison LP, Phelps CE, Basu A, Danzon PM. Defining elements of value in health care-a health economics approach: an ISPOR special task force report [3]. Value Health. 2018;21:131-9. https://doi.org/10.1016/j. jval.2017.12.007.

11. NICE. 2017. Interim process and methods of the highly specialised technologies programme updated to reflect 2017 changes. NICE, London. https://www.nice.org.uk/Media/Default/About /what-we-do/NICE-guidance/NICE-highly-specialised-techn ologies-guidance/HST-interim-methods-process-guide-may- 17. pdf. Accessed 2 Apr 2020.

12. Raftery J. NICE and the challenge of cancer drugs. BMJ. 2009;338:b67. https://doi.org/10.1136/bmj.b67.

13. Sharpe E, Hoey R, Yap C, Workman P. From patent to patient: analysing access to innovative cancer drugs. Drug Discovery Today. 2020. https://doi.org/10.1016/j.drudis.2020.01.004.

14. Barnsley P, Cubi-Molla P, Fischer A, Towse A. Uncertainty and risk in HTA decision making. OHE research paper. London: Office of Health Economics; 2016.

15. The Conservative and Unionist Party. 2019. Manifesto 2019. The Conservative and Unionist Party, London. https://assets-globa 1.website-files.com/5da42e2cae7ebd3f8bde353c/5dda924905 da587992a064ba_Conservative\%202019\%20Manifesto.pdf. Accessed 2 Apr 2020.

16. HM Treasury. 2018. The green book: central government guidance on appraisal and evaluation. HM Treasury, London. https://asset s.publishing.service.gov.uk/government/uploads/system/uploads/ attachment_data/file/685903/The_Green_Book.pdf. Accessed 2 Apr 2020.

17. Claxton K, Paulden M, Gravelle H, Brouwer W, Culyer AJ. Discounting and decision making in the economic evaluation of health-care technologies. Health Econ. 2011;20:2-15. https://doi. org/10.1002/hec.1612.

18. Oliver A. A normative perspective on discounting health outcomes. J Health Serv Res Policy. 2013;18:186-9. https://doi. org/10.1177/1355819613485671.

19. Paulden M, Galvanni V, Chakraborty S, Kudinga B, McCabe C. 2016. Discounting and the evaluation of health care programs. CADTH, Ottawa. https://www.cadth.ca/sites/default/files/pdf/ CP0008_Economic_Evaluation_Guidelines_Discount_Rate_ Report.pdf. Accessed 2 Apr 2020.

20. Attema AE, Brouwer WBF, Claxton K. Discounting in economic evaluations. PharmacoEconomics. 2018;36:745-58. https://doi. org/10.1007/s40273-018-0672-z.

21. Paulden M, Claxton K. Budget allocation and the revealed social rate of time preference for health. Health Econ. 2012;21:612-8. https://doi.org/10.1002/hec.1730. 